\title{
General Discussion to papers of F. X. Keane, J. C. Chawla et al., A. G. Key et al., H. W. F. Jones and A. Evans
}

Chairman: DR V. PAeslack (Germany)

Prof. M. Weiss (Poland). We believe that training for wheelchair posture is a goal of rehabilitation and should be made in stages. A patient should know that when the time comes to start to sit, it is a new position for him and he must understand that at this moment he is not prepared for that. From this point of view any feed-back system which was presented here is a very useful device but quite expensive, and we can replace it with good physiotherapy which would show the paraplegic how to lift himself from time to time and to understand that his weight-bearing surfaces are not valuable enough to support his weight. In our population we observe that use of physical activity and early sport application can help us in preventing bedsores. We are not observing many recurring sores following sport activities. I do believe that it is due to the fact that all general compensatory circulatory supply is better when the patient is applying physical activity. This is one of the reasons why we support the sport activities so strongly. The problem is what to do with tetraplegics, and here I was happy to hear those papers from South Africa as well as the polyester cushion application. We shall remember that a polyester mattress is the best trasportation tool we have now at our disposal. When we are dealing with acute cases and transport our patients in the position as he was found at the place of injury, the polyester mattress with vacuum is the best tool to keep the position until we can see the patient. The polyester system is excellent for measurement and application and relief of bedsores. When you take a polyester cushion and you insert foam pads underneath, then you can apply the vacuum in stages, using your electrical power system and pump. We applied a local ventilator under the feet to bring down heat. In a tetraplegic using his wheelchair for a longer period such a ventilator, applied from time to time, can be easily included.

Mr P. Harris (G.B.). Could Dr Keane remind us of the cost of the Rota Rest bed? The second question is to Dr Key about the maximum acceptable pressure, how much does this depend on the patient's weight? And the comment thirdly, is that a year ago at this meeting Sir Ludwig, in the current August number of the journal, those of us in Edinburgh gave a paper on the Simpson-Edinburgh Low Pressure Air Bed. Now one's idea turns towards a low pressure seat and this is a thought we will hopefully discuss this in the future. Two questions; one point.

Dr V. Paeslack. Mr Keane will you answer and Dr Key too.

Dr F. X. KeAne (Ireland). The first question is what is the cost of a Rota Rest bed. The simple home version is a $£$ IOoo, and I think the other large spinal bed is being sold for 4000 dollars now in the States.

Dr PAeslack. Thank you, Dr Keane.

Dr A. Key (South Africa). I should like to ask Mr Manley, the originator of this cushion, to answer that question.

Mr M. MANLEY (South Africa). There is "I think" a slight misunderstanding between the differences between pressure and weight. Pressure is independent of weight; pressure is load divided by the area to which it acts, and so the pressures quoted on the slide are in fact relevant for any type of body size, weight or shape. Actually while I am standing up can I make one of two points about Dr Keane's two papers. I think he has got a basic misconception about the way that body weight is transferred to the ground be it while the patient is lying or be it while the patient is sitting. He seems to think that a natural surface is by definition hard as the earth is hard. If you study the way in which a patient or a person lies in the natural environment, if you look at the way tribesmen live in the Amazon or any other part of the world where people do not have the advantages that we have in civilisation, even the stupidest person will put grass underneath him when 
he sits or lies, and sitting I do not believe is a natural state at all. I don't think the Creator as $\mathrm{Dr}$ Keane put it, ever designed mankind to sit. If you look at the way natural man rests when he is not lying; he crouches, he doesn't sit at all. I don't think that the two bony prominences at the base of the pelvis were ever designed by anybody to provide bilateral stability. We therefore have to supply a system in which a person can operate in a modern environment and the way in which we accept people in a modern environment is sitting unfortunately, and that being so we have to design a support surface which will cope with our customary way of carrying on.

DR P. Dolfus (France). I am pleased that Dr Keane mentioned the urethra. I think that the cushion is in fact one of the four or five causes of urethral obstructions a sitting patient can have. I myself, I am a polio and I am experiencing all the time this obstruction and it is not possible for a person who has a dysuria to add an obstacle to the bladder outlet. Now, I would like to ask Dr Key if she has noticed any improvements of the patient's dysuria by using her cushion. The South Africans have not only sent us in their good cushion but they have also sent the patient with the cushion too, so we appreciate it very much.

Dr M. Agerholme (G.B.). I would like to make a plea in relation to all these sitting devices and cushions, that we should consider every time the business of what is now called the logistics. Obviously, I learned years ago about pressure sores and how they were created from the main source (Sir Ludwig), and the whole principle of the sore being treated. I think, we all accept but our problem in dealing with it is surely being able to get the right cushion to the right person all the time, and I accept absolutely that a paraplegic ought to learn, as Professor Weiss says, to move himself around. So we are finally brought back to the people who cannot do that, who cannot shift their weight, and the design-I have ended up with the ripple seat which has been rather condemned I think by one speaker, because I find it doesn't need personal fitting. I know it needs electricity which is a problem and you ought to have two cushions so that when one isn't working you can use the other, but it has got all sorts of advantages such as that it doesn't have to be specially fitted and designed for the person.

I'd like to ask Dr Key if it would be universally available in a country like this where we theoretically have got a health service, but we haven't got easy access to our spinal injury centres, who is going to fit these cushions to these people and alter them when, I gather, the weight changes? I admire the cushion but I can't see it being any use to me and my patients. The question is does it have to be altered-very often they put weight on when they leave us-or is it a thing that is going to last the next 30 years without medical intervention?

DR J. C. Chawla (G.B.). I'd like to ask Dr Keane and Dr Key a question. They have taken into account the pressure; what about the shearing force because shear is also responsible for causing a pressure sore or a decubitus? The second point I should like to ask Dr Keane. According to the design of his chair he would expect his patient to sit I2 hours a day in upright posture, and not slump. What happens if he slumps forward? Does it come and hit his sacrum when you lift him up? The third point in answer to Professor Weiss about a feed-back which we develop; I agree that a fundamental principle is for the therapists to teach their patients, but as we have shown there are certain groups of patients who will never learn, and I think that we can make a device which in this country may not cost more than three or four pounds which will teach them to lift when they go home.

Dr F. W. MeINECKE (Germany). One question to $\mathrm{Dr}$ Key as well as to $\mathrm{Dr}$ Jones. Did you have any difficulties with the balance in those people with high lesions, i.e. upper thoracic and tetraplegics? Secondly, to Dr Jones. I enjoyed his paper very much on polyester but learning from one slide of yours, I do feel this is not very suitable in patients who are propelling their wheelchair by themselves because it is a hindrance and not an advantage. answer.

PROF. PAeslack. Thank you very much. I ask now the speakers of the morning to

Prof. A. Rossier (U.S.A.). Just one question to Dr Key. I agree with the shearing 
effect, I am just interested in what seems to be a paradoxical effect. In fact you have emphasised the detrimental sagging effect of the wheelchair. Couldn't it be beneficial in a way, although it will defeat the adductor spasticity or increase it possibly, but you are going to shift the weight from the ischii also to the trochanterics since the sagging will create a much larger surface. I'm just questioning it from personal experience. So I am just asking, did you measure the different pressures with purposely sagging effect in order to see the respective surface ischi versus trochanter?

Sir Ludwig GutTManN (G.B.). I would like to ask Dr Keane at what stage of paraplegia he has made this examination. This seems to me a very important point and secondly, have you done this research by producing these bilateral ischaemias experimentally or were these patients who were admitted immediately after injury and if so I would like to know in what stage of the paralysis you have done it? I was a bit puzzled about your interesting demonstration with regard to pressure and I was wondering whether we have done our management with our simple procedures to treat and prevent pressure sores in the acute and early stages of spinal cord injuries really properly. I am satisfied that the principles I have laid down regarding vertical pressure as well as shearing stress still hold. I feel that we were correct in considering in addition to the sensory loss, the lowering of tissue resistance not merely of the skin but also of the muscles resulting from the crippled vasomotor control in the paralysed part as the main cause of pressure sores. However, the vasomotor control recovers in later stages, and consequently so does the tissue resistence to pressure unless there is interference of the vasomotor control by a major acute infection. It is not correct to say, as you did, that consideration to prevent pressure sore is only or mainly given to skin tissues.

I was sitting here next to my pupil Alain Rossier, who is a complete paraplegic of the mid-thoracic region for many years. He has been lifting-and I watched himonly every three-quarters of an hour and I think he does it more or less regularly like this, yet he has never developed a sore. Nor have I discovered pressure sores on the emaciated boy whose photograph Dr Keane demonstrated. I agree with you on one point, that without the regular turning, you said of $20 \mathrm{~min}$, a sore may develop. That might be so in the acute stage under special circumstances although we haven't seen it by proper turning, especially using the Egerton-Stoke Mandeville turning and tilting bed which is now used in many countries. I'd like to know in what stages you have done your experiments.

PRof. V. PAeslack. May I now ask the speakers of this morning to answer the different questions that have been put in the discussion? May I first ask Dr Keane?

Dr F. X. Keane (Ireland). Well, I would like to answer Sir Ludwig, first of all, because he was the one that suggested turning his patients half-hourly. He wanted to know I think what type of patient we used, in the sitting experiments?

Sir Ludwig GutTMann. At what stage?

DR F. X. KEANE. In what stage? The patients that were seated on the glass were out of the acute stage of paraplegia and they were just simply asked to sit up in a chair and support it and then we photographed the buttocks from underneath. I did bring out the point that very slight movement on a normal, what I would call a natural surface, will in fact relieve the pressure on the ischia so the slightest movement will probably keep a patient comfortable sitting on his tuberosities on a natural surface, but once you put the cushion under him he now sinks so far into the cushion that he has to make a gross effort to lift. These experiments were done in the later stages of paraplegia. The point you make about the vascular disturbances in the early stages of paraplegia; the patients we have nursed with decubiti have both been in the acute and later stages of paraplegia and any intercurrent infections, as Sir Ludwig pointed out, are the cause and you go back to your initial vascular disturbance stage of the early period. Under those conditions if you continuously turn your patient the decubiti will heal, through the acute phase. Was that all the questions Sir Ludwig?

Sir Ludwig GuttmanN. Well you didn't tell us at what time they developed that remarkable picture of bilateral ischaemia which is most unusual. Moreover, you didn't tell us about the female patient with an indwelling catheter hanging down. When she sits, of course, there is a double pressure, pressure through the weight of her body and 
through the catheter from the inside of the bladder. Have you ever done X-rays of the symphysis? You talked all the time about the ischial ramus but of as much importance can be the symphysis. You may find that in some of the patients the symphysis has gone and there is separation of the two rami. Perhaps you would care to answer this too.

DR F. X. KeANE. Yes. Well we just simply sat the patient on this horizontal sheet of glass and the spot you get these two areas marked out. From the point of view of the female patient I'm not quite certain what Sir Ludwig means, but all I'm suggesting is that the shape of a toilet seat will do as a support means for a matter of minutes. I would not like to see a patient's buttocks unsupported for hours for the simple reason that you will encourage other complications such as haemorrhoids which are a common problem in paraplegia, and then as far as I see, if you have a permanent cut in a patient's cushion you are going to encourage haemorrhoids. I have not X-rayed symphysis while sitting on the toilet seat.

The next problem I think was put to me was that man always gets grass together and makes himself a bed to lie down. Well in my comparative studies between animal anatomy and human anatomy there are more superficial bony prominences in man than in any other terrestrial animal and I would say that this is so because man's unique brain requires him to assume many more postures than most other animals and it is simple to study. You will find that active muscle does in fact cross bony prominences in animals and obviously has more efficient muscle because the muscle is longer. like for instance in the leg of the chicken who never kneels down to say his prayers. The meat runs right across his knee and gives him a longer and more efficient muscle for there is no necessity to protect that muscle because he doesn't kneel, and whereas he does sit on a roost and the keel as they call it in the skeleton of the chicken is not covered by an active organ muscle. Now the point was raised is that we must accept that modern man sleeps on a soft surface. Of course that's natural that we use a soft surface. My point is that you must be very careful that a soft surface is all right for the normal healthy individual with sensation and mobility but it is a deadly surface for somebody that's paralysed and without sensation. I believe that these bony prominences are there to support the skeleton and if you want an extreme case of protective role the brain is totally surrounded by bone: an example of where bony prominences are used to protect vital tissue.

There is just one other point about sitting in a slumped position. Apparently it doesn't matter in what postion you sit or lie as long as you have sensation and you move often enough, or on what surface you lie. So if a patient has say fixed flexion contractures of the hips, he will not be able to assume an upright sitting posture in a wheelchair and therefore he slumps in the chair, and in the reciprocating seat you use a reclining back on your chair and let him sit on the sacrum because you are lifting him every $4 \frac{1}{2}$ min. I think they were all the questions there were.

Prof. V. PAeslack. You will now answer the questions Dr Key.

Dr A. Key (South Africa). I'd like to ask Dr Manley to reply to two of them. Firstly the question concerning the urethra and dysuria. We haven't had any trouble at all other than with female patients with catheters and for this we have cut a gutter for the catheter to lie in. As far as the fitting of the cushions are concerned I will ask Dr Manley to answer that one but just to say that in South Africa commercially available are the small, medium and large cushions referring of course to the cut-out size and we feel that this is adequate. The problems with fitting they can be dealt with. The shear forces, I did mention that it is terribly important to have a flat surface to sit on, we have found we have had terrible trouble recently with wheel chairs, this is another story, but we have wheelchair seats that sag within 3 weeks of being used and it is destroying our cushion programme. It must have a flat surface to sit on. Dr Rossier, I feel that increasing the surface area, agreed it does do that but it adds to your shear pressure forces by having a sag. The balance of the patients I think Dr Meinecke asked that, the balance is undoubtedly improved in all cases. Initially a number of patients found the cushion different and those four that didn't use it were the ones who gave up too quickly. One patient who didn't like it at all because he said he felt unsure in his chair 
and the balance was different, eventually lost his cushion, it dropped off the roof of his car and he nearly drove us crazy, he souldn't use any other cushion. Once they get used to it they don't want anthing else.

DR M. MANLEY (S.A.) We have managed in fact to get away with cushions in small, medium and large sizes and the way we've done it is to put a block of low-density foam into the cut-out and that has two functions. That allows the ischial tuberosities to take a small proportion of body weight and that small proportion of body weight reduces oedema and the risk of haemorrhoids, of course, and means that the cushion dimension, the lateral side to side dimension of the cushion cut-out doesn't have to be completely critical. You can get away with small, medium and large cushions and we can now do it at a glance. You know you can just look at somebody and more or less decide whether they want a small, medium or large cushion. That's no problem. There was one point about shear forces. There is also a misconception about shear forces. People when they talk about shear forces assume does the patient tend to slide forward in the chair. No. Can you just tell me exactly what you mean because any two areas which are loaded differently will have shear forces applied between them. If you load one area of skin with say $20 \mathrm{~mm}$ of mercury and an inch away you load another area of skin with $50 \mathrm{~mm}$ of mercury then the shear coming between those two areas vertically into the tissue not horizontally along the tissue but vertically into the tissue.

We did realise that was a problem when we first designed the cushion and initially we had a square cut out into a square cushion. What we have done more recently is to contour the cushion slightly-if you look at them the contouring is fairly simple, but it does mean that we do not get a sudden change in load between the almost no-load situation on the ischial tuberosities and the high-load situation on the back of the thighs, there was this gradual transfer of load as the cushion slopes to the thighs. This means that shear force transmission across that area is fairly small and we don't have problems.

Prof. Paeslack. I think we have time for one last question to $\mathrm{Mr}$ Jones.

Dr Francis Jones (G.B.). You pointed out a weakness which we have also encountered at this stage and not only the question of propelling the wheelchair but even of making a tidy transfer is at at present difficult with the cushion in its present form.

PROF. PAESLACK. So we will close for the moment our discussion, have coffee and because we are out of our timetable I ask you to meet again here at 12.15. 